\title{
Comparative study of hydrochlorothiazide and indapamide on the anti-atherogenic potential of losartan in cholesterol fed rat
}

\author{
Md. Zakirul Islam and Md. Sayedur Rahman \\ Department of Pharmacology, Bangabandhu Sheikh Mujib Medical University, \\ Shahbag, Dhaka 1000, Bangladesh.e-mail:srkhasru@bdcom.com
}

\begin{abstract}
The study was conducted to evaluate the anti-atherogenic potential of losartan and to assess the effects of hydrochlorothiazide and indapamide on losartan activity in rat. Cholesterol diet $(0.5 \%)$ for 12 weeks led to significant hyperlipidemia, increased body weight and oxidative stress in erythrocyte. While, losartan, hydrochlorothiazide and indapamide treatment continued for next 12 weeks, losartan showed anti-atherogenic activity reflected by hypolipidemic effect and antioxidant effect in erythrocyte. This activity was abolished by addition of hydrochlorothiazide with losartan but remained unaltered by addition of indapamide with losartan. Atherosclerotic change and oxidative stress were not found in rat aorta, which may be due to short duration and low dose of cholesterol feeding. Hydrochlorothiazide treatment was associated with hypokalemia, which was not present in losartan or indapamide treatment. This study suggests that indapamide might be co-administered with losartan conserving the essential anti-atherogenic potential of losartan.
\end{abstract}

\section{Introduction}

Hyperlipidemia is a well-established major risk factor for the development and progression of atherosclerosis and its associated conditions as ischemic heart disease $\&$ cerebrovascular disease ${ }^{1}$. Atherogenesis is initiated as an inflammatory response to injury, usually with cholesterol ${ }^{2}$. The renin-angiotensin system is known to be involved in atherogenesis through promotion of endothelial dysfunction and oxidative modification of LDL cholesterol by angiotensin $\mathrm{II}^{3}$. Angiotensin II Type 1 receptor blockers (ARBs) like losartan may have an important role contributing to attenuation of atherogenic process independent of lowering blood pressure $^{4}$. Furthermore, losartan was well tolerated at high doses required for its additional pharmacological benefits ${ }^{5}$.

The addition of either a thiazide diuretic as hydrochlorothiazide or the thiazide-like indoline indapamide to an ARB results in further reduction in blood pressure ${ }^{6}$. Hydrochlorothiazide is known to raise the blood concentration of total cholesterol, low-density lipoproteins and triglycerides both in high and low doses ${ }^{7}$. A study describes that combination therapy of hydrochlorothiazide with ACE inhibitor can abolish the beneficial effect of ACE inhibitor with regard to endothelial function and atherosclerosis ${ }^{8}$.
It is claimed that standard doses of indapamide are metabolically neutral, specifically with regard to lipid profile?. Indapamide reduces the progression and development of atherosclerotic lesions ${ }^{7}$. Therefore, the present study aims to find out a thiazide diuretic that can be added to ARBs in hypertension treatment conserving the beneficial anti-atherogenic effect of ARBs.

\section{Materials and Methods}

Chemicals and reagents: Cholesterol powder $\geq 99 \%$ was procured from E. Merck, Germany. Cholesterol, triglycerides and HDL cholesterol assay kit were procured from Randox Laboratories, UK. Trichloroacetic acid, disodium hydrogen phosphate, 5,5'-dithio-bis-2-nitrobenzoic acid (DTNB), reduced glutathione (GSH) and thiobarbituric acid were procured from Sigma Aldrich, Germany. All other chemicals used were of analytical grade. Losartan potassium, hydrochlorothiazide and indapamide were obtained from Square Pharmaceuticals Limited (Bangladesh).

Animals: The study was carried out on Long Evans Norwegian strains of adult healthy rats of both sexes. The rats were 2-3 months aged and weighing between 150-160 g. Rats were housed in standard stainless cages. They were allowed living at room temperature in a clean, well ventilated rodent room 
where a 12/12 hours light/dark cycle was maintained. They were fed on standard pellets of rat food and allowed to drink ad libitum.

Experimental design: The study was conducted in two parts. In part I, 90 rats were divided into 3 groups and fed standard rat diet in group A consisted of 10 rats, soybean oil in Group B consisted of 10 rats and $0.5 \%$ cholesterol-enriched diet in Group C consisted of 70 rats, for 12 weeks. 10 rats of Group A, Group B and Group C were sacrificed under chloroform anesthesia at the end of 12 weeks and the remaining 60 rats of Group $\mathrm{C}$ were continued to part II of the study. In part II, 60 rats were divided into 6 groups each consisted of 10 rats and all groups were fed $0.1 \%$ cholesterolenriched diet with losartan (25 $\mathrm{mg} / \mathrm{kg} /$ day $)$ in Group II, hydrochlorothiazide $(12.5 \mathrm{mg} / \mathrm{kg} /$ day $)$ in Group III, indapamide (1.25 mg/kg/day) in Group IV, losartan (25 mg/kg/day) plus hydrochlorothiazide $(12.5 \mathrm{mg} / \mathrm{kg} /$ day $)$ in Group $\mathrm{V}$ and losartan (25 mg/kg/day) plus indapamide (1.25 mg/kg/day) in Group VI, for next 12 weeks and at the end they were sacrificed under chloroform anesthesia. Rats were kept fasting overnight the day before sacrifice.

Body weight measurement: Properly calibrated analogue weight measurement machine was used to measure body weight of rats. In part I of the study body weight of 30 rats was measured at day 0 and after 12 weeks. In part II of the study body weight of 60 rats was measured at day 0 , after 12 weeks and after 24 weeks.

Sample collection: Blood samples were collected by cutting throat with sharp blade and were treated with and without heparin. The aorta was dissected out and divided into two parts. The upper part of the aorta was packed in separate polyethylene packets with accurately labeled and preserved at $20^{\circ} \mathrm{C}$ until the period of analysis. The lower part of the aorta was preserved in separate accurately labeled container with $10 \%$ formal saline for histopathological study.

Preparation of erythrocytes: Heparinized blood samples were centrifuged at 4,000 rpm for $5 \mathrm{~min}$ and the plasma and buffy coat was discarded by removing from the top. The packed RBCs were washed three times with five volumes buffered saline $(0.9 \%$ saline in $10 \mathrm{mM}$ phosphate buffer, $\mathrm{pH}$ 7.4) by centrifugation at $4,000 \mathrm{rpm}$ for $5 \mathrm{~min}$. The packed cells were then suspended in an equal volume of the distilled deionized water to lyse RBCs.

Preparation of serum: Blood samples without heparin were centrifuged at 4,000 rpm for $5 \mathrm{~min}$ and the serum was collected by pasture pipette into labeled test tube.
Preparation of aortic tissue homogenate: Aortic tissue was cleaned properly in a petri dish containing Tyrode's solution at $0-4^{\circ} \mathrm{C}$ (resting in ice birth) and carefully weighed of $100 \mathrm{mg}$. Clean tissue was then chopped into small pieces and homogenated properly by a hand tissue homogenizer with $2 \mathrm{~mL}$ Tyrode's solution and keeping the homogenizer in the ice bath.

Estimation of serum cholesterol: Serum cholesterol was assayed by enzymatic (CHOD-PAP) method ${ }^{10}$. One $\mathrm{mL}$ of the cholesterol reagent was added to each of the test tubes containing $10 \mu \mathrm{L}$ of standard solution, $10 \mu \mathrm{L}$ of distilled water and $10 \mu \mathrm{L}$ of serum and the mixtures were mixed properly and incubated at $37^{\circ} \mathrm{C}$ for $5 \mathrm{~min}$. The absorbance was measured at $500 \mathrm{~nm}$ against the reagent blank using UV-Vis spectrophotometer.

Estimation of serum triglyceride: Serum triglyceride was assayed by enzymatic (GPO-PAP) method $^{11}$. One $\mathrm{mL}$ of the triglyceride reagent was added to each of the test tubes containing $10 \mu \mathrm{L}$ of standard solution, $10 \mu \mathrm{L}$ of distilled water and 10 $\mu \mathrm{L}$ of serum and the mixtures were mixed properly and incubated at $37^{\circ} \mathrm{C}$ for $5 \mathrm{~min}$. The absorbance was measured at $500 \mathrm{~nm}$ against the reagent blank using spectrophotometer.

Estimation of serum HDL cholesterol: Serum HDL cholesterol was assayed by enzymatic (CHODPAP) method after precipitation of other lipid component of the sample ${ }^{12}$. One $\mathrm{mL}$ of the precipitant reagent was added to $500 \mu \mathrm{L}$ of the sample. Then the mixture was mixed properly, allowed to stand for $10 \mathrm{~min}$ at room temperature and centrifuged at 4,000 rpm for $10 \mathrm{~min}$. After that HDL cholesterol was assayed from the supernatant by enzymatic (CHOD-PAP) method.

Estimation of serum LDL cholesterol: Serum LDL cholesterol was calculated by Friedewald equation $^{13}$. LDL cholesterol $=$ Total cholesterol HDL cholesterol - Triglycerides/5.

Estimation of GSH: GSH level was assayed by Ellman's method ${ }^{14}$. In brief, $1 \mathrm{~mL}$ of aortic tissues homogenate and erythrocytes was added to $1 \mathrm{~mL}$ of $5 \%$ trichloroacetic acid and the mixture was vortexes and centrifuged at 4,000 rpm for $5 \mathrm{~min}$. Then $250 \mu \mathrm{L}$ of supernatant was added to $2 \mathrm{~mL}$ $\mathrm{Na}_{2} \mathrm{HPO}_{4}(4.25 \%)$ and $250 \mu \mathrm{L}$ of DTNB (0.04\%). The mixture was allowed to stand for approximately $10 \mathrm{~min}$, and forming a yellow substance. The absorbance was measured at 412 nm using spectrophotometer.

Estimation of MDA: MDA (malondialdehyde) level was assayed by thiobarbituric acid reaction method $^{15}$. In brief, $1 \mathrm{~mL}$ of aortic tissues 
homogenate and erythrocytes was added to $4.5 \mathrm{~mL}$ of $5.5 \%$ trichloroacetic acid and the mixture was vortexed and centrifuged at 4,000 rpm for $5 \mathrm{~min}$. Then $1 \mathrm{~mL}$ of supernatant was added to $1 \mathrm{~mL}$ of $0.67 \%$ thiobarbituric acid. The mixture was kept in a water bath at $100^{\circ} \mathrm{C}$ for $10 \mathrm{~min}$ and forming a pink substance. The absorbance was measured at $532 \mathrm{~nm}$ using spectrophotometer. MDA content was calculated in $\mathrm{mol} / \mathrm{L}$ using the molar extinction coefficient for MDA that is $1.56 \times 10^{5}$. Then it is multiplied by $10^{9}$ for conversion to $\mathrm{nmol} / \mathrm{L}$.

Estimation of serum electrolytes: Serum sodium, potassium and chlorine level were assayed by ion selective electrode method using Nova Electrolyte 4 Analyzer (Nova biomedical corporation, USA).

Histopathological procedure: The aorta was fixed in $10 \%$ formalin, dehydrated in graded alcohol and embedded in paraffin wax, sectioned at $5 \mu \mathrm{m}$ thickness and stained with hematoxylin and Eosin (H\&E) for microscopic examination. Microscopically the lesion of the aorta was graded according to stary's classification ${ }^{16}$. Photomicrographs were taken from the representative histopathological sections of each group using a digital camera fitted with microscope. Intima-media ratio was measured using Image pro plus software (Media Cybernetics, USA).
Statistical analysis: Statistical analysis was done by Statistical Package for Social Science (SPSS), version 16 for windows. The quantitative variables were expressed as mean \pm SEM. ANOVA (multiple comparisons) was done for statistical analysis. Post hoc analyses of differences were done by Bonferroni ' $t$ ' test.

\section{Results}

Losartan decreased serum cholesterol, triglyceride, LDL-C \& increased HDL-C level, but hydrochlorothiazide increased serum cholesterol, triglyceride, LDL-C \& decreased HDL-C level. Indapamide showed no effects on serum lipid profile in comparison to control group (Table I). Coadministration of hydrochlorthiazide with losartan diminished the hypolipidaemic effect of losartan, whereas conadiminisrration of indapamide did not interfere the effect of losartan.

The body weights of the rats were decreased with losartan, increased with hydrochlorothiazide and not changed with indapamide (Table II). In comparison to losartan treated rats, body weight increased when hydrochlorothiazide and losartan were co-administered and not changed when indapamide and losartan were co-administered.

Table I: Effect of drug treatment on serum lipid level of $0.5 \%$ cholesterol-fed rats

\begin{tabular}{|c|c|c|c|c|}
\hline Group & $\begin{array}{c}\text { Serum cholesterol } \\
(\mathrm{mg} / \mathrm{dL})\end{array}$ & $\begin{array}{c}\text { Serum triglycerides } \\
(\mathrm{mg} / \mathrm{dL})\end{array}$ & $\begin{array}{c}\text { Serum HDL } \\
\text { cholesterol }(\mathrm{mg} / \mathrm{dL})\end{array}$ & $\begin{array}{c}\text { Serum LDL } \\
\text { cholesterol }(\mathrm{mg} / \mathrm{dL})\end{array}$ \\
\hline Control & $108.94 \pm 1.78$ & $81.59 \pm 1.41$ & $40.50 \pm 0.87$ & $52.12 \pm 1.97$ \\
\hline Losartan & $84.24 \pm 1.21 *$ & $73.44 \pm 1.17^{*}$ & $45.97 \pm 0.68 *$ & $23.58 \pm 0.76^{*}$ \\
\hline Hydrochlorothiazide & $125.82 \pm 1.23^{*}$ & $88.14 \pm 1.30^{*}$ & $32.16 \pm 1.38^{*}$ & $76.03 \pm 2.00^{*}$ \\
\hline Indapamide & $104.63 \pm 1.19$ & $77.06 \pm 1.11$ & $37.94 \pm 1.01$ & $51.28 \pm 1.08$ \\
\hline Losartan + Hydrochlorothiazide & $121.80 \pm 1.31^{\mathrm{a}}$ & $83.77 \pm 1.23^{\mathrm{a}}$ & $31.69 \pm 0.92^{\mathrm{a}}$ & $73.36 \pm 1.87^{\mathrm{a}}$ \\
\hline Losartan + Indapamide & $82.80 \pm 1.20$ & $71.67 \pm 1.22$ & $43.58 \pm 1.40$ & $24.89 \pm 1.15$ \\
\hline
\end{tabular}

Values are mean $\pm \mathrm{SEM} ; \mathrm{n}=10 ;{ }^{*} \mathrm{p}<0.01$ compared to control group as analyzed by ANOVA (multiple comparisons by Bonferroni ' $\mathrm{t}$ ' test); ${ }^{\mathrm{a}} \mathrm{p}<0.001$ compared to losartan treated group as analyzed by ANOVA (multiple comparisons by Bonferroni ' $t$ ' test)

Table II: Effect of drug treatment on body weight of $0.5 \%$ cholesterol-fed rats

\begin{tabular}{lccc}
\hline Group & \multicolumn{3}{c}{ Body weight (g) } \\
\cline { 2 - 4 } & Day 0 & 12 weeks & 24 weeks \\
\hline Control & $155.50 \pm 0.93$ & $258.30 \pm 0.76$ & $290.00 \pm 1.32$ \\
Losartan & $154.40 \pm 0.99$ & $256.80 \pm 1.00$ & $281.80 \pm 1.23^{*}$ \\
Hydrochlorothiazide & $155.10 \pm 0.60$ & $257.20 \pm 0.96$ & $299.10 \pm 2.16^{\mathrm{a}}$ \\
Indapamide & $155.40 \pm 0.76$ & $256.40 \pm 0.87$ & $288.60 \pm 0.96$ \\
Losartan + Hydrochlorothiazide & $154.80 \pm 1.01$ & $255.50 \pm 1.02$ & $291.20 \pm 1.41^{\mathrm{a}}$ \\
Losartan + Indapamide & $155.80 \pm 0.83$ & $256.30 \pm 0.82$ & $280.50 \pm 0.93$ \\
\hline
\end{tabular}

Values are mean $\pm \mathrm{SEM} ; \mathrm{n}=10 ;{ }^{*} \mathrm{p}<0.01$ compared to control group as analyzed by ANOVA (multiple comparisons by Bonferroni ' $\mathrm{t}$ ' test); ${ }^{\mathrm{a}} \mathrm{p}<0.001$ compared to losartan treated group as analyzed by ANOVA (multiple comparisons by Bonferroni ' $t$ ' test) 
Table III: Effect of drug treatment on GSH and MDA levels in erythrocyte \& aortic tissue of $0.5 \%$ cholesterol-fed rats

\begin{tabular}{|c|c|c|c|c|}
\hline \multirow[t]{2}{*}{ Group } & \multicolumn{2}{|c|}{ GSH level } & \multicolumn{2}{|c|}{ MDA level } \\
\hline & $\begin{array}{c}\text { Erythrocyte } \\
(\mathrm{mg} / \mathrm{g} \mathrm{Hb})\end{array}$ & $\begin{array}{l}\text { Aortic tissue } \\
\text { (mg/g tissue) }\end{array}$ & $\begin{array}{l}\text { Erythrocyte } \\
\text { (nmol/g Hb) }\end{array}$ & $\begin{array}{c}\text { Aortic tissue } \\
\text { (nmol/g tissue) }\end{array}$ \\
\hline Control & $8.86 \pm 0.29$ & $4.04 \pm 0.14$ & $10.08 \pm 0.24$ & $1.61 \pm 0.07$ \\
\hline Losartan & $10.11 \pm 0.36^{*}$ & $4.11 \pm 0.17$ & $8.30 \pm 0.11^{*}$ & $1.48 \pm 0.07$ \\
\hline Hydrochlorothiazide & $7.44 \pm 0.20^{*}$ & $3.92 \pm 0.11$ & $11.02 \pm 0.19^{*}$ & $1.75 \pm 0.06$ \\
\hline Indapamide & $8.97 \pm 0.20$ & $4.02 \pm 0.20$ & $9.89 \pm 0.17$ & $1.59 \pm 0.08$ \\
\hline Losartan + Hydrochlorothiazide & $7.52 \pm 0.20^{\mathrm{a}}$ & $3.88 \pm 0.10$ & $10.84 \pm 0.17^{\mathrm{a}}$ & $1.55 \pm 0.09$ \\
\hline Losartan + Indapamide & $10.23 \pm 0.30$ & $4.13 \pm 0.17$ & $8.18 \pm 0.13$ & $1.50 \pm 0.11$ \\
\hline
\end{tabular}

Values are mean $\pm \mathrm{SEM} ; \mathrm{n}=10 ;{ }^{*} \mathrm{p}<0.01$ compared to control group as analyzed by ANOVA (multiple comparisons by Bonferroni ' $\mathrm{t}$ ' test); ${ }^{\text {a }} \mathrm{p}<0.001$ compared to losartan treated group as analyzed by ANOVA (multiple comparisons by Bonferroni ' $t$ ' test)

Losartan have antioxidant effect observed by increased GSH and decreased MDA levels in erythrocyte. Hydrochlorothiazide decreased GSH and increased MDA levels in erythrocyte. In indapamide treated rats, there was tendency of increase in GSH and decrease in MDA levels in erythrocyte but the changes were not significant (Table III). The antioxidant effect of losartan was abolished with addition of hydrochlorothiazide, which effect was conserved while indapamide was added with losartan.
Morphological study of aortic tissue of rats revealed that there was no atherosclerotic change in the aorta. There were no significant changes observed in intima-media ratio of the aorta. There were no significant changes in serum electrolyte level in losartan and indapamide treated rats and in rats where losartan and indapamide were coadministered. Hypokalemia was observed in hydrochlorothiazide treated rats and also in rats where hydrochlorothiazide was added with losartan (Table IV).

Table IV: Effect of losartan, hydrochlorothiazide, indapamide, losartan plus hydrochlorothiazide and losartan plus indapamide on morphology of aortic tissue and serum electrolytes level of $0.5 \%$ cholesterol-fed rats

\begin{tabular}{|c|c|c|c|c|}
\hline Group & $\begin{array}{c}\text { Intima-media ratio of } \\
\text { aorta }\end{array}$ & $\begin{array}{l}\text { Serum sodium } \\
(\mathrm{mmol} / \mathrm{L})\end{array}$ & $\begin{array}{c}\text { Serum potassium } \\
(\mathrm{mmol} / \mathrm{L})\end{array}$ & $\begin{array}{c}\text { Serum chloride } \\
(\mathrm{mmol} / \mathrm{L})\end{array}$ \\
\hline Control & $0.54 \pm 0.01$ & $147.30 \pm 1.14$ & $7.09 \pm 0.07$ & $86.70 \pm 0.52$ \\
\hline Losartan & $0.55 \pm 0.02$ & $146.40 \pm 0.43$ & $6.51 \pm 0.16$ & $87.40 \pm 0.31$ \\
\hline Hydrochlorothiazide & $0.57 \pm 0.01$ & $146.40 \pm 0.43$ & $5.51 \pm 0.12$ & $87.50 \pm 0.27$ \\
\hline Indapamide & $0.53 \pm 0.01$ & $147.00 \pm 0.67$ & $6.56 \pm 0.13$ & $87.40 \pm 0.40$ \\
\hline $\begin{array}{l}\text { Losartan }+ \\
\text { Hydrochlorothiazide }\end{array}$ & $0.56 \pm 0.02$ & $147.00 \pm 0.79$ & $5.62 \pm 0.21$ & $86.80 \pm 0.68$ \\
\hline Losartan + Indapamide & $0.55 \pm 0.01$ & $146.70 \pm 0.62$ & $6.60 \pm 0.17$ & $86.90 \pm 0.75$ \\
\hline
\end{tabular}

Values are mean $\pm \mathrm{SEM} ; \mathrm{n}=10 ;{ }^{*} \mathrm{p}<0.01$ compared to control group as analyzed by ANOVA (multiple comparisons by Bonferroni ' $\mathrm{t}$ ' test); ${ }^{\mathrm{a}}<0.001$ compared to losartan treated group as analyzed by ANOVA (multiple comparisons by Bonferroni 't' test)

\section{Discussion}

In the present study, serum cholesterol, triglyceride \& LDL-C level was decreased and HDL-C level was increased by losartan, which resembles to the finding of a previous study ${ }^{17}$. Hypolipidemic benefit of losartan in this study may be due to its decreasing effect of lipoprotein(a) [Lp(a)] and fibrinogen level ${ }^{18}$. Serum cholesterol, triglyceride \& LDL-C level was increased and HDL-C level was decreased by hydrochlorothiazide but indapamide had no effects on serum lipid profile. Both of these results support the finding of another earlier study ${ }^{7}$. Changes in lipid profile level by hydrochlorothiazide could be attributable to its effect on cholesterol metabolism probably via alteration in receptors for cholesterol uptake, increase in the level of $\mathrm{Lp}(\mathrm{a})$ and interference on the enzyme of cholesterol metabolism ${ }^{18}$. Indapamide had no effect on lipid profile because it has no deleterious effect on cholesterol metabolism? .

The hypolipidaemic effect of losartan was diminished when hydrochlorothiazide was coadministered with losartan, whereas the effect was conserved when indapamide was coadministered with losartan. The observation might be explained by the fact that the above mentioned hyperlipidaemic mechanisms of hydrochlorothiazide perhaps interferes the beneficial effect of losartan on lipid profile; 
whereas this hypolipidemic effect of losartan was conserved with indapamide, which have neutral or no effect on cholesterol metabolism? .

Body weights of the rats were decreased with losartan, increased with hydrochlorothiazide and not changed with indapamide. In comparison to losartan treated rats, body weight increased when hydrochlorothiazide and losartan were coadministered and not changed when indapamide and losartan were co-administered. These effects on body weight may correlates with the changes in serum lipid profile produced by losartan, hydrochlorothiazide and indapamide ${ }^{19}$.

The present study revealed that losartan exerted antioxidant effect observed by increased GSH and decreased MDA levels in erythrocyte, which might be due to its effect of blocking the angiotensin II mediated oxidative stress, which is similar to the findings of other study ${ }^{20}$. Hydrochlorothiazide treated rats demonstrate decreased GSH and increased MDA levels in erythrocyte. The result elucidate that hydrochlorthiazide has no antioxidant effect, which corresponds to the finding of another study $^{21}$. Although the changes were not significant, indapamide treated rats showed tendency of increase in GSH and decrease in MDA levels in erythrocyte, which is similar in another study ${ }^{22}$. However, antioxidant effect of losartan was abolished with co-administration of hydrochlorothiazide. This might be due to attenuation of nitric oxide (NO) mediated endothelial antioxidant mechanism of losartan by hydrochlorothiazide ${ }^{23}$. While the antioxidant effect of losartan was conserved in rats, in which indapamide was added with losartan. This might be explained by the fact that indapamide have antioxidant property of its own and exerts its effect without interfering the antioxidant mechanism of $\operatorname{losartan}^{24}$.

Morphological study of aortic tissue of rats in the present study revealed that there was no atherosclerotic change in the aorta as well as there were no significant changes observed in intimamedia ratio of the aorta among different groups of rats. This might be explained by the fact that the duration of cholesterol enriched diet feeding was short or the amount of cholesterol in the rat diet was just only adequate to produce hyperlipidemia but not to develop atherosclerosis. However, these findings differ from the results of previous studies conducted in other species may be due to different and weaker anti-inflammatory and antioxidant mechanism in vascular endothelium than rat ${ }^{25}$.

Atherosclerotic change in the aortic tissue was not observed in rats after 24 weeks, irrespective of drug received. This might be due to the fact that oxidative stress usually not evidenced in aortic tissue of rats irrespective of the treatment received and is assumed to be related to presence of additional antioxidant mechanism in aortic tissue of $\mathrm{rat}^{26}$.

In this study, there was no significant changes in serum electrolyte level in losartan treated rats. Though, it has been reported earlier that losartan sometimes causes hyperkalemia ${ }^{27}$. Indapamide treated rats showed no alteration in serum electrolytes level. However, hypokalemia and hyponatremia have been reported to be associated with indapamide treatment ${ }^{28}$. There was hypokalemia in hydrochlorothiazide treated rats and also in rats where hydrochlorothiazide was added with losartan. This finding conforms to the previous reports of hypokalemia associated with hydrochlorothiazide. However in those studies, there were occasional reports of hyponatremia and hypochloremia $^{29}$, which was not observed in the present study. Another study suggested a relationship between hypokalemia and atherosclerosis. So, hydrochlorothiazide-induced hypokalemia may be responsible for its atherogenic effect ${ }^{30}$.

In conclusion, the present study reaffirms the antiatherogenic benefit of losartan reflected by its' hypolipidemic effects. The study reveals that coadministration of hydrochlorothiazide abolishes that anti-atherogenic benefit of losartan and coadministration of indapamide does not hinder the anti-atherogenic benefit of losartan.

\section{References}

1. Grundy SM, Cleeman JI, Merz CN, Brewer HB Jr, Clark LT, Hunninghake DB, Pasternak RC, Smith SC Jr, Stone NJ. Implications of Recent Clinical Trials for the National Cholesterol Education Program Adult Treatment Panel III Guidelines. Circulation 2004; 110 : 227-39.

2. Libby P. Changing concepts of atherogenesis. J Intern Med. 2000; 247: 349-58.

3. Strehlow K, Wassmann S, Bohm M, Nickenig G. Angiotensin AT1 receptor over-expression in hypercholesterolaemia. Ann Med. 2000; 32: 386-89.

4. Hoque R, Rahman MS, Iqbal M. Effect of enalapril and losartan on proteinuria in type 2 diabetic nephropathy patients. Bangladesh Med Res Counc Bull. 2009; 35: 44-48.

5. Hayek T, Attias J, Coleman R, Brodsky S, Smith J, Breslow JL, Keidar S. The angiotensin-converting enzyme inhibitor, fosinopril, and the angiotensin II receptor antagonist, losartan, inhibit LDL oxidation and attenuate atherosclerosis independent of lowering blood pressure in apolipoprotein $\mathrm{E}$ deficient mice. Cardiovasc Res. 1999; 44: 579-87. 
6. Cremonesi G, Cavalieri L, Cikes I, Dobovisek J, Bacchelli S, Degli Esposti D, Costa FV, Borghi C, Ambrosioni E. Fixed combinations of delapril plus indapamide vs fosinopril plus hydrochlorothiazide in mild to moderate essential hypertension. Adv Ther. 2002; 19: 129-37.

7. Ames RP. A comparison of blood lipid and blood pressure responses during the treatment of systemic hypertension with indapamide and with thiazides. Am J Cardiol. 1996; 77: 12B-16B.

8. Fonseca FA, Ihara SS, Izar MC, Silva EP, Kasinski N, Lopes IE, Pinto LE, Paiva TB, Tufik S, de Paola AA, Carvalho AC. Hydrochlorothiazide abolishes the antiatherosclerotic effect of quinapril. Clin Exp Pharmacol Physiol. 2003; 30: 779-85.

9. Gerber A, Weidmann P, Bianchetti MG, Ferrier C, Laederach K, Mordasini R, Riesen W, Bachmann C. Serum lipoproteins during treatment with the antihypertensive agent indapamide. Hypertension 1985; 7: II164-69.

10. Richmond W. Preparation and properties of a cholesterol oxidase from Nocardia sp. and its application to the enzymatic assay of total cholesterol in serum. Clin Chem. 1973; 19: 1350-56.

11. Fossati P, Prencipe L. Serum triglycerides determined colorimetrically with an enzyme that produces hydrogen peroxide. Clin Chem. 1982; 28: 2077-80.

12. Lopes-Virella MF, Stone $\mathrm{P}$, Ellis S, Colwell JA. Cholesterol determination in high-density lipoproteins separated by three different methods. Clin Chem. 1977; 23: 882-84.

13. Friedewald WT, Levy RI, Fredrickson DS. Estimation of the concentration of low-density lipoprotein cholesterol in plasma, without use of the preparative ultracentrifuge. Clin Chem. 1972; 18: 499-502.

14. Ellman GL. Tissue sulfhydryl groups. Arch Biochem Biophys. 1959; 82: 70-77.

15. Srour MA, Bilto YY, Juma M. Evaluation of different methods used to measure malondialdehyde in human erythrocytes. Clin Hemorheol Microcirc. 2000; 23: 2330.

16. Stary HC, Chandler AB, Dinsmore RE, Fuster V, Glagov S, Insull W Jr, Rosenfeld ME, Schwartz CJ, Wagner WD, Wissler RW. A definition of advanced types of atherosclerotic lesions and a histological classification of atherosclerosis: A report from the committee on vascular lesions of the council on arteriosclerosis, American Heart Association. Circulation 1995; 92: 1355-74.

17. Imanishi $\mathrm{T}$, Kuroi $\mathrm{A}$, Ikejima $\mathrm{H}$, Kobayashi $\mathrm{K}$, Muragaki Y, Mochizuki S, Goto M, Yoshida K, Akasaka T. Effects of angiotensin converting enzyme inhibitor and angiotensin II receptor antagonist combination on nitric oxide bioavailability and atherosclerotic change in Watanabe heritable hyperlipidemic rabbits. Hypertens Res. 2008; 31: 575-84.

18. Papadakis JA, Ganotakis ES, Jagroop IA, Mikhailidis DP, Winder AF. Effect of hypertension and its treatment on lipid, lipoprotein(a), fibrinogen, and bilirubin levels in patients referred for dyslipidemia. Am J Hypertens. 1999; 12: 673-81.

19. Chobanian AV, Haudenschild CC, Nickerson C, Drago R. Anti-atherogenic effect of captopril in the Watanabe heritable hyperlipidemic rabbit. Hypertension 1990; 15: $327-31$

20. Polizio AH, Peña C. Effects of angiotensin II type 1 receptor blockade on the oxidative stress in spontaneously hypertensive rat tissues. Regul Pept. 2005; 128: 1-5.

21. Kedziora-Kornatowska K, Czuczejko J, SzewczykGolec K, Motyl J, Szadujkis-Szadurski L, Kornatowski T, Pawluk H, Kedziora J. Effects of perindopril and hydrochlorothiazide on selected indices of oxidative stress in the blood of elderly patients with essential hypertension. Clin Exp Pharmacol Physiol. 2006; 33: 751-56.

22. Breugnot $\mathrm{C}$, Iliou JP, Privat $\mathrm{S}$, Robin $\mathrm{F}$, Vilaine JP, Lenaers A. In vitro and ex vivo inhibition of the modification of low-density lipoprotein by indapamide. J Cardiovasc Pharmacol. 1992; 20: 340-47.

23. Alvarez Y, Pérez-Girón JV, Hernanz R, Briones AM, García-Redondo A, Beltrán A, Alonso MJ, Salaices M. Losartan reduces the increased participation of cyclooxygenase-2-derived products in vascular responses of hypertensive rats. J Pharmacol Exp Ther. 2007; 321: 381-88.

24. Vergely C, Walker MK, Zeller M, Rademakers JR, Maupoil V, Schiavi P, Guez D, Rochette L. Antioxidant properties of indapamide, 5-OH indapamide and hydrochlorothiazide evaluated by oxygen-radical absorbing capacity and electron paramagnetic resonance. Mol Cell Biochem. 1998; 178: 151-55.

25. Miyazaki M, Sakonjo H, Takai S. Anti-atherosclerotic effects of an angiotensin converting enzyme inhibitor and an angiotensin II antagonist in Cynomolgus monkeys fed a high-cholesterol diet. Br J Pharmacol. 1999; 128: 523-29.

26. Balkan J, Dog ru-Abbasog`lu S, Aykac-Toker G, Uysal M. The effect of a high cholesterol diet on lipids and oxidative stress in plasma, liver and aorta of rabbits and rats. Nutr Res. 2004; 24: 229-34.

27. Kauffmann R, Orozco R, Venegas JC. Severe hyperkalemia associated to the use of losartan and spironolactone: Case report. Rev Med Chil. 2005; 133: 94752.

28. Chapman MD, Hanrahan R, McEwen J, Marley JE. Hyponatraemia and hypokalaemia due to indapamide. Med J Aust. 2002; 176: 219-21.

29. McInnes GT, Shelton JR, Harrison IR, Perkins RM, Rigby GV. Diuretic induced hypokalaemia: Relationship to dosage interval and plasma aldosterone. Br J Clin Pharmacol. 1982; 14: 449-52.

30. Andrew ME, Jones DW, Wofford MR, Wyatt SB, Schreiner PJ, Brown CA, Young DB, Taylor HA. Ethnicity and unprovoked hypokalemia in the Atherosclerosis Risk in Communities Study. Am J Hypertens. 2002; 15: 594-99. 
